\title{
Digital Customer Experience \\ An Emerging Theme in Customer Service Excellence
}

\section{Grønholdt, Lars}

Document Version

Final published version

Publication date:

2019

\section{License \\ CC BY-NC-ND}

Citation for published version (APA):

Grønholdt, L. (2019). Digital Customer Experience: An Emerging Theme in Customer Service Excellence. Paper presented at 22nd QMOD-ICQSS International Conference on Quality and Service Sciences, Krakow, Poland.

Link to publication in CBS Research Portal

\section{General rights}

Copyright and moral rights for the publications made accessible in the public portal are retained by the authors and/or other copyright owners and it is a condition of accessing publications that users recognise and abide by the legal requirements associated with these rights.

\section{Take down policy}

If you believe that this document breaches copyright please contact us (research.lib@cbs.dk) providing details, and we will remove access to the work immediately and investigate your claim. 


\title{
Digital customer experience: An emerging theme in customer service excellence
}

\author{
Lars Grønholdt \\ Professor, Department of Marketing \\ Copenhagen Business School, Denmark \\ lg.marktg@cbs.dk
}

\begin{abstract}
Purpose - The purpose of the paper is to examine how essential dimensions of digital customer experience (DCE) drive business performance.

Methodology/approach - An empirical study is conducted to investigate the relationships between seven DCE dimensions and business performance. The conceptual model is operationalized by a structural equation model, and the model is estimated and tested by using the partial least squares method. A survey of 756 companies in Denmark forms the empirical basis for the study.
\end{abstract}

Findings - The findings provide evidence that the seven DCE dimensions influence business performance. All seven DCE dimensions are essential in producing total customer experience, market performance, and financial performance.

Research limitations - The study is limited to the seven identified DCE dimensions in Danish companies.

Practical implications - The study has clear implications in terms of identifying and measuring the importance of essential DCE dimensions which influence business performance. Interesting differences appear between the seven indexes for DCE dimensions. The results can help companies to understand DCE and develop DCE strategies.

Originality/value - The paper provides insight into DCE and how DCE works.

Key words Digital customer experience, market performance, financial performance

Paper type Research paper 


\section{Introduction}

In recent years, creating and managing digital customer experiences seems to be a key area for many companies on "leveraging digital advancement for the growth of organizations and achieving sustained commercial success” (Bones and Hammersly, 2017, p. 128). Digital advancements has attracted great attention from marketing academics and practitioners (Borowski, 2015; Cliff, 2018; Lywood et al., 2009; Palmer, 2008, 2010; Verhoef et al., 2009). Sharma and Chaubey (2014, p. 18) claim that "the customer experience has emerged as the single most important aspect in achieving success for companies across all industries".

The literature on customer experience is growing fast, and the debate among scholars and practitioners is very lively. However, "the greatest challenge for customer experience management lies in the difficulty of measuring the concept, which is specific to a situational and emotional context” (Palmer, 2008). Moreover, Brakes et al. (2009, p. 52) state that "research has largely ignored the exact nature and dimensional structure of brand experiences". The present study addresses these challenges and examines how digital customer experience (DCE) can be measured and how different dimensions of DCE influence business performance.

The present study is initiated and conducted as a research project between Copenhagen Business School, Denmark (CBS, www.cbs.dk) and House of Loyalty, Denmark (www.sj@stigjorgensen.as) with the support of several Danish data, insights and consulting companies.

The structure of the paper is as follows. Firstly, the essential dimensions of DCE are identified and discussed. Secondly, a conceptual model of the relationships between the DCE dimensions and business performance is developed. Thirdly, the research methodology is presented: measures development, data collection, and the modelling approach. Fourthly, data analyses results are presented and discussed. And fifthly, concluding remarks are provided in the closing section of the paper.

\section{Linking DCE to business performance}

Based on literature reviews (i.a., McColl-Kennedy et al., 2015; Gupta, 2018), case studies from the literature (i.a., Frow and Payne, 2007; Gupta, 2018), and practical work with DCE an initial frame of reference of DCE was developed. This outlined a set of characteristics of DCE describing relevant areas of actions in the company: Top management anchoring and digital strategy, culture, customer journey, customer insight and data, innovation, organization, and competences (see the conceptual model in Figure 1).

For each of the areas, survey questions are developed based on Shaw (2017) and practical work with DCE surveys. An empirical study (see next section) suggest that it would be appropriate to organize the initial DCE characteristics in seven DCE dimensions. Hence, analyzing survey responses from 484 companies using factor analysis (see next section) gave new insight into how to structure and describe the DCE concept with good sense. The seven dimensions (factors) are shown on the left-hand side of the conceptual model (see Figure 1).

\section{Figure 1. The conceptual DCE model}




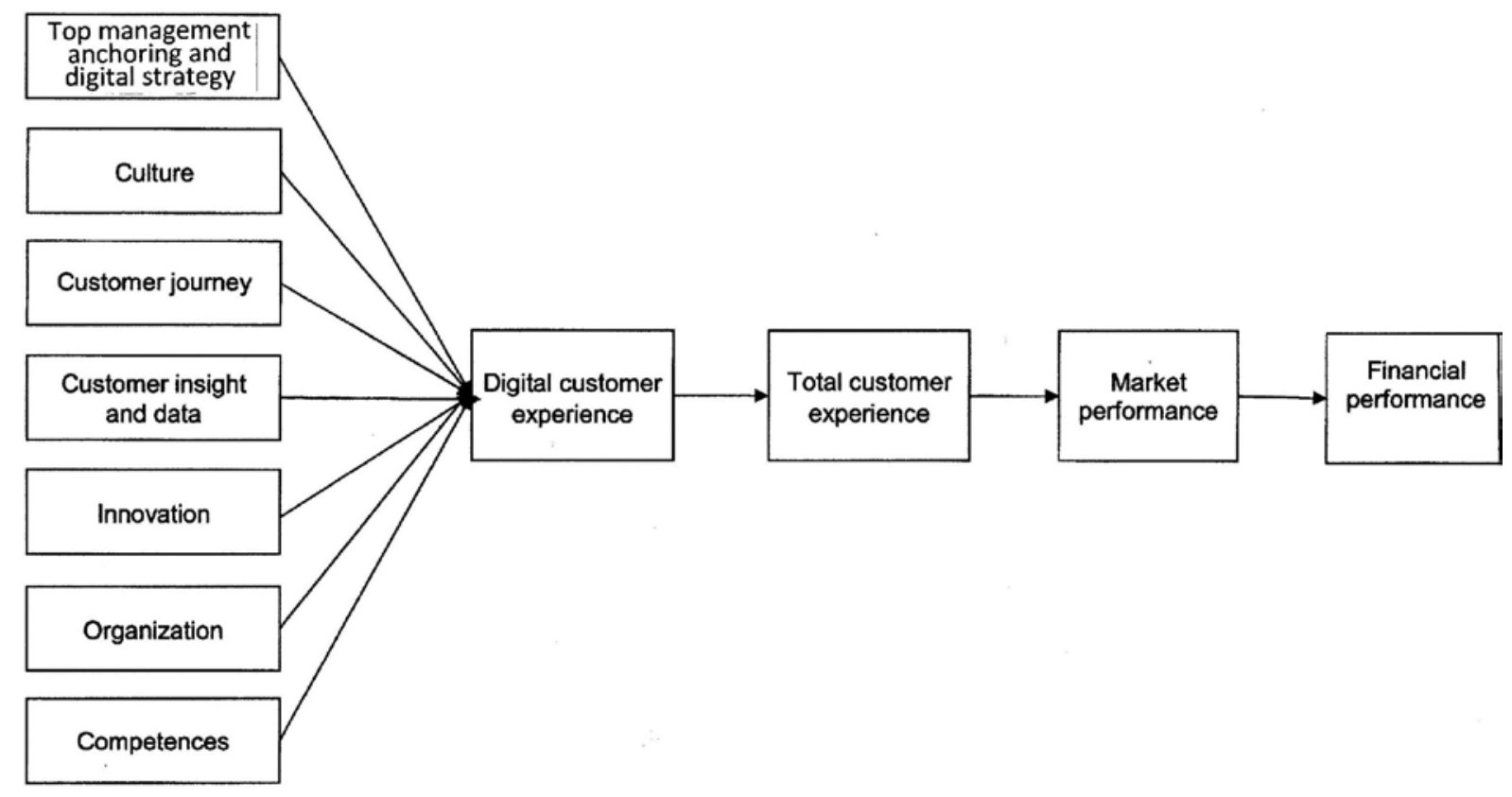

The conceptual model in Figure 1 shows the links between DCE dimensions, DCE, total customer experience, market performance, and subsequently financial performance.

\section{Methodology}

\section{Measures development}

The conceptual model's eleven variables are viewed as latent variables, which are measured by 2-6 measurement variables or items (measured by survey questions). The seven dimensions of DCE have been deduced from literature studies and confirmative and explorative factor analysis. The model structure is at this moment supported by data which in turn makes good sense to the model (face validity).

The survey questions which have been used to measure the seven DCE dimensions are partly inspired by Shaw's work with customer experience in general (Shaw, 2017), partly based on practical work with measuring DCE and customer experience, and partly developed for the this study explicitly.

Measurements of market performance and financial performance have been done by using established scales from academic literature: Desphandé et al. (1993), Homburg and Pflesser (2000), Moorman and Rust (1999), and Zhou et al. (2009).

All questions are generic which means they are formulated in such a flexible manner that they can be used across companies and industries. At this moment, the estimation results can be compared across companies and industries which allow using the results in benchmarking studies. It is a distinct advantage for this model and the attached measurement system. The developed questionnaire consists of 44 questions regarding DCE and total customer experience, and 10 questions regarding the two business performance variables. 
The respondent answers all questions on a 7-point scale. Questions regarding DCE and total customer experience concern the respondent's company. The respondent is asked to mark from 'strongly disagree' to 'strongly agree' on the statements provided. Answers to questions regarding market and financial performance are to be scaled from 'much worse' to 'much better' compared to competitors.

\section{Data collection}

In 2019 we conducted an online survey across several industry and service sectors in Denmark to capture a broad variety of market settings. Our unit of analysis is the company, and the data contains 484 useable interviews with company managers in Denmark. Most of the managers held top management positions such as marketing manager, director (responsible for marketing and sales activities within the company) or member of the executive.

\section{A structural equation modeling approach}

The conceptual model in Figure 1 is operationalized as a structural equation model which links each latent variable with the corresponding measurement variables (the measurement model) and links the latent variables through causal relationships (the structural model) symbolized by the arrows in Figure 1.

The structural equation model is estimated and tested by using partial least squares (PLS) due to this method's advantages: PLS is distribution-free and it is robust (against skew distributions for measurement variables and multicollinearity) (Cassell et al., 1999; Chin, 1998; Fornell and Bookstein, 1982; Hulland, 1999; Tenenhaus et al., 2005). Furthermore, PLS is a powerful method for predictive applications, as PLS aims at explaining variances (Fornell and Cha, 1994).

We follow the recommended two-stage analytical procedure for the PLS approach to structural equation modeling (Fornell and Larcker, 1981; Hair et al., 2012; Hulland, 1999): Firstly, the measurement model was evaluated, and then the structural model including estimation and testing of the model. In both stages, the software SmartPLS (Ringle et al., 2019) was used.

\section{Data analysis results}

\section{Measurement model evaluation}

Initially, several analyses were carried out to assess the measurement variables (items) and the latent variables in the model.

The reliability and validity of the scales were examined. Firstly, item reliability was measured by Cronbachs' alfa factor loading. We found from the SmartPLS output that the lowest loading was 0.72 , indicating that item reliability of the scale measures was acceptable. It is recomended, that Cronbach's alpha of an item is 0.7 or more (Carmines and Zeller, 1979; Hulland, 1999).

Secondly, composite reliability (internal consistency) was assessed using the composite reliability coefficient recommended by PLS researchers, and an acceptable level is said to be 0.7 or higher (Baumgartner and Homburg, 1996; Chin, 1998; Fornell and Larcker, 1981; Hulland, 1999). We found that all composite reliability coefficients were higher than 0.85 and 
exceeded the recommended threshold. Also, we used the average variance extracted (AVE), which should be higher than 0.5 (Chin, 1998; Fornell and Cha, 1994; Fornell and Larcker, 1981). The AVE for all latent variables clearly exceeds this condition, since the lowest reported AVE value is 0.60 , demonstrating composite reliability for all latent variables also in that way. Thirdly, discriminant validity is present if the square root of AVE of a latent variable is more extensive than its correlations with the other latent variables (Chin, 1998; Fornell and Larcker, 1981; Hulland, 1999). The criterion is met for all latent variables, which indicates that the latent variables in the model are distinct. Thus, with acceptable reliability and validity assessments, our measures were considered to be appropriate for subsequent estimation and test of the causal model.

\section{Estimation of the DCE model}

The results of the PLS estimation of the model are shown in Figure 2. The estimates of the impacts (path coefficients) between the latent variables in the model are displayed by the arrows, and DCE indexes, total customer experience and performance indexes are shown inside the variables in the figure. As expected, all estimated impacts are positive. The estimated indexes for each variable - from 0 (poor) to 100 (excellent) - indicate the average level among the participating companies in the study. The impact scores are effects of a one-point increase in a variables' index on the following variable.

To test the significance of the path coefficients the bootstrap resampling procedure is applied, and all relationships in the model are statistically significant (all t values $>17.6$, all $p$ values $<$ $0.001)$.

By estimating the model an explanatory power of $\mathrm{R}^{2}=0.61$ for financial performance is achieved, i.e., the model explains $61 \%$ of the variation in financial performance. For market performance and total customer experience, the explanatory power is respectively $R^{2}=0.53$ and $\mathrm{R}^{2}=0.56$. These $\mathrm{R}^{2}$ values indicate a good overall model fit.

In conclusion, the quality of the model is good with strong explanatory power. Thus, there is a high certainty and precision in the results and conclusions to be drawn from the study.

\section{Results and discussion}

\section{Clear evidence of the relationship between DCE and financial performance}

The model estimation results show that there is a strong relationship between DCE and financial performance as illustrated in Figure 2. All DCE dimensions have a positive influence on digital customer experience, which in turn has a positive and significant influence on both market performance and financial performance. Moreover, as expected, market performance influences financial performance.

\section{Figure 2. The estimated DCE model}




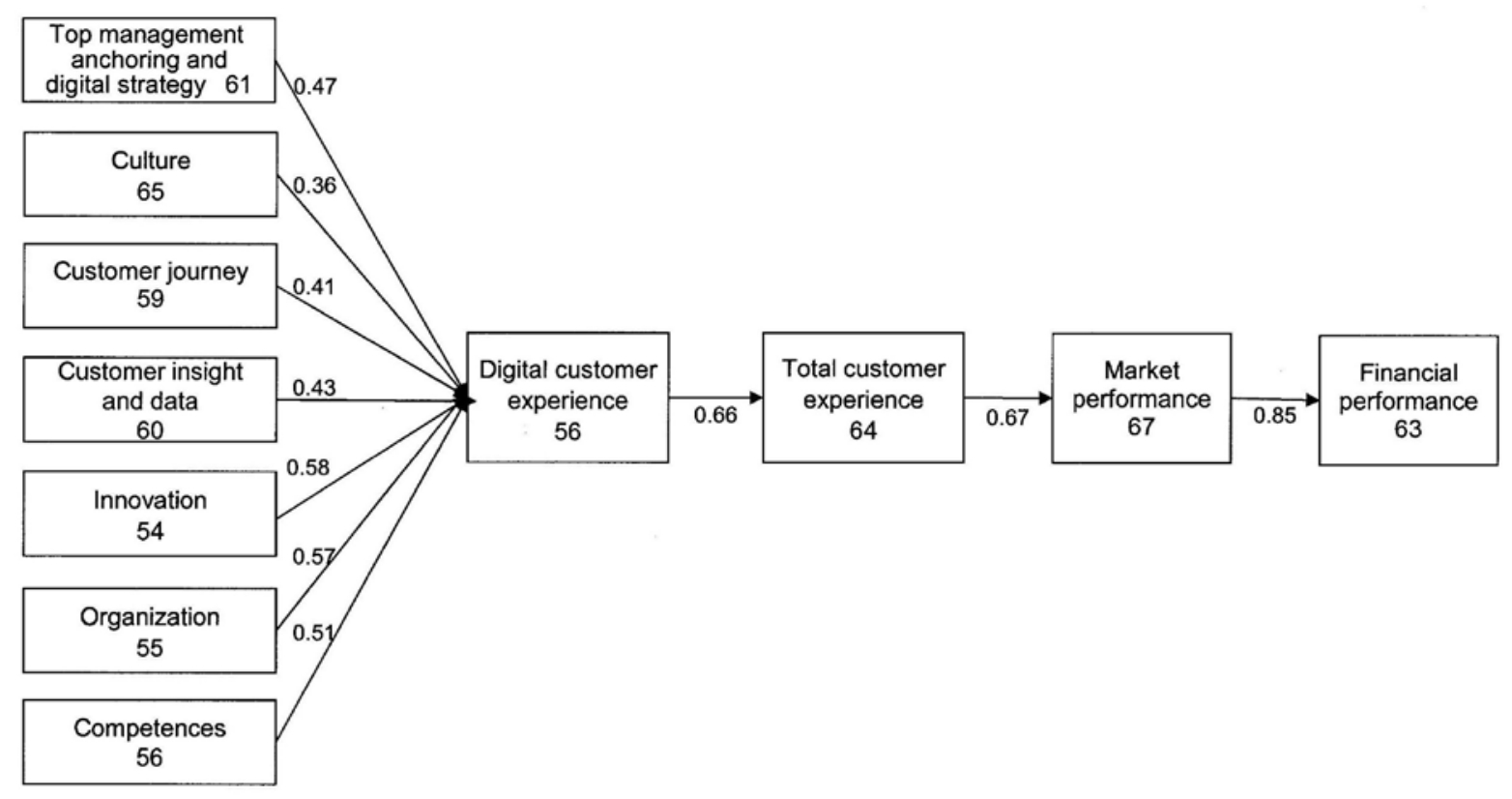

\section{Differences between the DCE dimensions}

Interesting differences can be observed between the seven indexes for DCE dimensions. The three lowest indexes is for innovation, organization, and competences. It is noticeable that these three DCE dimensions have the largest impact on DCE. Against this background, companies in general should generally focus on improving innovation, organization and competences with a view to increasing DCE, total customer experience, market performance, and finally financial performance.

\section{Conclusion}

The present paper has investigated DCE and its influence on business performance. The developed DCE model provides a comprehensive means of covering important dimensions of DCE as well as a better understanding of these dimensions' link to business performance. The seven DCE dimensions make good sense to Danish managers. The model has been empirically validated, and all relationships in the model are statistically significant indicating a solid model. The quality of the model is good with strong explanatory power, and the conclusions drawn from the study reflect high confidence and precision.

The data analyses presented in the paper provide evidence that all seven DCE dimensions influence business performance.

The presented model is limited to seven identified DCE dimensions. It is possible that an alternative structure of the dimensions or new dimensions - cf. the introductory remarks on the growing literature and debate on DCE - may provide even more convincing conclusions.

The study is the second of a yearly DCE index that measures DCE based on the same survey set-up and modeling approach as presented in this paper. Some survey questions are added in 2019 to reveal actual DCE themes and trends. 


\section{References}

Baumgartner, H., and Homburg, C. (1996), “Applications of structural equation modeling in marketing and consumer research: A review", International Journal of Research in Marketing, Vol. 13, pp. 139-161.

Bones, C., and Hammersley, J. (2017), "Leading digital strategy: Driving digital strategy: Driving business growth through effective e-commerce", The Journal of Decision Makers, Vol. 42, No. 2, pp. 128-132.

Borowski, C. (2015). "What a great digital customer customer experience actually looks like”, Harvard Business Review, Vol. 11, No. 9, pp. 2-5.

Carmines, E.G., and Zeller, R.A. (1979), Reliability and Validity Assessment, Sage University Paper Series on Quantitative Applications in the Social Sciences, No. 07-017. Sage, Beverly Hills, California.

Cassel, C., Hackl, P., and Westlund, A.H. (1999). "Robustness of partial least-squares method for estimating latent variable quality structures”, Journal of Applied Statistics, Vol. 26, No. 4, pp. 435-46.

Chin, W.W. (1998), ”The partial least squares approach to structural equation modeling”, in: Marcoulides, G.A. (Ed.), Modern Methods for Business Research (pp. 295-336). Lawrence Erlbaum Associates, Mahwah, New Jersey.

Cliff, S. (2018), "Why the digital customer experience reguires a business transformation", Computer Weekly, No. 3, Vol. 20, pp. 28-32.

Deshpandé, R., Farley, J.U., \& Webster Jr., F. (1993), ”Corporate culture, customer orientation, and innovativeness in Japanese firms: A Quadrad analysis”, Journal of Marketing, Vol. 57, No. 1, pp. 23-37.

Fornell, C. and Bookstein, F.L (1982), "Two structural equation models: LISREL and PLS applied to consumer exit-voice theory”, Journal of Marketing Research, Vol. 19, No. 4, pp. 440-452.

Fornell, C. and Cha, J. (1994), "Partial least squares”, in: R.P. Bagozzi (Ed.), Advanced Methods of Marketing Research (pp. 52-78). Blackwell, Cambridge, Massachusetts.

Fornell, C. and Larcker, D.F. (1981), "Evaluating structural equation models with unobservable variables and measurement error”, Journal of Marketing Research, Vol. 18, No. 1, pp. 3950 .

Gupta, S. (2018), Driving Digital Strategy, Harvard Business Review Press, Boston, Massachusetts.

Hair, J.F., Sarstedt, M., Pieper, T.M., and Ringle, C.M. (2012), "The use of partial least squares structural equation modeling in strategic management research: A review of past practices and recommendations for future applications”, Long Range Planning, Vol. 45, No. 5/6, pp. 320-340.

Homburg, C. and Pflesser, C. (2000), "A multiple-layer model of market-oriented organizational culture: Measurement issues and performance outcomes”, Journal of Marketing, Vol. 37, No. 4, pp. 449-462.

Hulland, J. (1999), "Use of partial least squares (PLS) in strategic management research: A review of four recent studies”, Strategic Management Journal, Vol. 20, No. 2, pp. 195-204.

Hwang, J. and Seo (1999), "A critical review of research on customer experience management”, International Journal of Contemporary Hospitality Management, Vol. 28, No. 10, pp. 2218-2246.

Lywood, J., Stone, M., and Ekinci, Y. (2009), "Customer experience and profitability: An application of the empathy rating index (ERIC) in UK call centres”, Journal of Database Marketing and Customer Strategy Management, Vol. 16, No. 3, pp. 207-214. 
Moorman, C. and Rust, R.T. (1999). "The role of marketing”, Journal of Marketing, Vol. 63, No. 4, pp. 180-197.

Palmer, A. (2008), "The role of the 'customer experience manager' - Hope or hype?", Proceedings of the 10th International Research Seminar in Services Management, La Londe, France, 27-30 May 2008.

Palmer, A. (2010), "Customer experience management: a critical review of an emerging idea”, Journal of Services Marketing, Vol. 24, No. 3, pp. 196-208.

Pine, B.J. and Gilmore, J.H. (1998), The Experience Economy, Harvard Business School Press, Boston, Massachusetts.

Ringle, C.M., Wende, S., and Will, A. (2019), SmartPLS, University of Hamburg, available at: www.smartpls.com

Schmitt, B. (1999). Experimental Marketing: How to Get Customers to Sense, Feel, Think, Act and Relate to Your Company and Brands, The Free Press, New York, NY.

Sharma, M. and Chaubey, D.S. (2014). "An empirical study of customer experience and its relationship with customer satisfaction towards the services of banking sector”, Journal of Marketing \& Communication, Vol. 9, No 3, pp. 18-27.

Shaw, J.D. (2017). "From the editors: Advantages of starting with theory", Academy of Management Journal, Vol. 60, No. 3, pp. 819-822.

Tenenhaus, M., Vinzi, V.E., Chatelin, Y.-M., and Lauro, C. (2005). "PLS path modeling”, Computational Statistics and Data Analysis, Vol. 48, pp. 159-205.

Verhoef, P.C., Lemon, K.N., Parasuraman, A., Roggeveen, A., Tsiros, M., and Schlesinger, L.A. (2009), "Customer experience creation: Determinants, dynamics and management strategies”, Journal of Retailing, Vol. 85, No 1, pp. 31-41.

Zhou, K.Z., Brown, J.R., and Dev, C.S. (2009), ”Market orientation, competitive advantage, and performance: A demand-based perspective", Journal of Business Research, Vol. 62, No. 11, pp. 1063-1070. 